\title{
Bologna Process: elective lectures and internships in medical curriculum and the role of anatomy electives
}

\author{
Mustafa F. Sargon \\ Department of Anatomy, Faculty of Medicine, Hacettepe University, Ankara, Turkey
}

\begin{abstract}
Objectives: Due to objectives of Bologna Process, updated programs of School of Medicine, Hacettepe University were put into practice in 2013-2014 academic years. Progress of elective lectures and internships in undergraduate medical education and the role of anatomy were discussed. The outcomes of all data were obtained from the experiences of three academic years.

Methods: Before Bologna Process, electives were present in the curriculums of Phase I and VI. Beginning with this process; two elective committees were added to curriculums of Phase I-III. In Phase IV and V, electives were organized as being part of internship. The new approach to elective lectures and internships were discussed both from point of medical students and lecturers.

Results: Phase I-III students showed two major tendencies: choosing elective lectures related to medicine and choosing the ones which were in same campus. They also had two major complaints: difficulty of some electives and some undesired electives due to packaging system or related to extreme number of students. From the point of anatomy, students preferred to choose anatomy electives which were useful for anatomy curriculum. Lecturers complained from the extreme number of students, low number of electives and decreased number of theoretical hours. The extreme number of students and low number of electives seemed the major problems. Therefore, decreasing the number of elective lectures can be a solution. Additionally, the remaining time from these electives can be added to basic medical lectures.
\end{abstract}

Conclusion: Excited lecturers with ideal number of students can perform the best education. From the point of anatomy, many elective clinical anatomy lectures are essential for drawing the attention.

Keywords: anatomy electives; Bologna Process; elective lectures; medical curriculum, undergraduate medical education

Anatomy 2017;11(3):137-140 @2017 Turkish Society of Anatomy and Clinical Anatomy (TSACA)

\section{Introduction}

The European Ministers responsible for higher education in 29 countries were gathered in Bologna in June 19, 1999 and signed the Bologna declaration. ${ }^{[1]}$ They agreed on the development of a consistent and harmonious European Higher Education Area by 2010. One of the basic purposes for the European Higher Education Area was to strengthen the international competitiveness of European higher education for the undergraduate, postgraduate and doctoral graduate studies which have precisely defined duration..$^{[2-6]}$

Due to the objectives of Bologna Process, the updated programs of School of Medicine, Hacettepe University were put into practice in 2013-2014 academic years. One of the major changes in these programs was the addition of elective lectures and elective internships to the medical curriculum of undergraduate students of all six years (twelve semesters). In order to add these electives to the medical curriculum of undergraduate students, the lecture and practical hours of basic lectures were decreased $20 \%$ in all of the semesters.

The present study aimed to compare the updated programs of Bologna Process and the previous medical curriculum from the point of elective lectures in School of Medicine, Hacettepe University. The comparison was done both from the perspectives of medical students and 
lecturers in an experience of 2013-2014, 2014-2015 and 2015-2016 academic years. Related to these programs, progress of elective lectures and internships in undergraduate medical education were examined in the study. Additionally, the demands of undergraduate students to anatomy elective lectures were discussed.

\section{Materials and Methods}

In School of Medicine, Hacettepe University medical curriculum, elective lectures were present in the curriculum of Phase I throughout the entire academic year and in Phase VI till the end of the academic year 2012-2013. Before the beginning of 2013-2014 academic years, the medical curriculum was fully updated in accordance with the updated programs of Bologna Process. Two elective committees were added to the curriculums of Phase I, Phase II and Phase III. Each of these committees consisted of four elective lectures which were brought together to form a package. While making a package by these four elective lectures, a great care was shown for making the packages from the elective lectures of different departments. In every committee, $75 \%$ of these lectures (totally three lectures in each committee) were given by the lecturers of the Medical Faculty of Hacettepe University. The remaining $25 \%$ of elective lectures in each committee (one lecture) was given by the Faculty of Education of Hacettepe University. The medical students' major complaint about the lectures of Faculty of Education was the lecture halls which were situated in the other campus of the university. Therefore, the complaints of the students were taken into consideration and the lecturers were invited to the campus of Medical School lecture halls.

In the medical curricula of Phase IV and Phase V, there were no elective lectures before the updated programs of Bologna Process. Beginning from the academic year of 2013-2014, the electives were organized as being a part of internship and added to the final two weeks of the training program in Phase IV. These elective lectures were directly related with the present internship program and they aimed to give some detailed knowledge and practical applications related to the present internship program. In Phase $V$, three elective lectures were added to the medical curriculum and each of them was organized to be three weeks. The Bologna Process did not bring any change to the medical curriculum of Phase VI in School of Medicine, Hacettepe University. They still had two electives and medical students prefer one elective from medical sciences and the other one from surgical sciences divisions.

\section{Results}

In School of Medicine, Hacettepe University, in Phase I, Phase II and Phase III, the period of elective lecture packages were totally four weeks. Every week, each elective lecture had a lecture hour of four hours, and therefore, totally, each elective lecture had a total of 16 lecture hours in the committee. Additionally, due to the four elective lectures in a package; in every semester; the total lecture hours of electives were 64 hours in each elective committee.

The Phase I, Phase II and Phase III students showed two major tendencies: choosing the elective lectures related to medicine and choosing the ones which were given in the same campus of the university. Therefore, beginning from the first day of 2013-2014 academic year, all of the elective lectures were given in the lecture halls of the Medical School. They also had two major complaints: the difficulty of some elective lectures and some undesired elective lectures due to the packaging system of four elective lectures together. The extreme number of students (around 60 students in each package) was another undesired condition for the electives both from the point of undergraduate students and lecturers.

In Phase IV and V, the students did not have any complaints about the ongoing of the elective internships. In Phase IV, their only complaint was about the exam of the internship program. The medical students attended to two different oral examinations during their internship program. The first oral exam was done at the end of the internship program and the second was done at the end of the elective part of the internship program. Both of these two oral exams were independent from each other. In Phase V, the students attended to the exam of each elective lecture at the end of each internship. The Phase VI students did not have any complaints about the elective internship programs in their medical curriculum.

From the point of lecturers of Phase I, Phase II and Phase III, the major complaint was the extreme number of students and low number of elective lectures. These lecturers had many choices for grading at the end of the electives. Preparing test questions, giving home works and attendance can all or only one be used for grading in these three years. In Phase IV and Phase V, the only method of grading was done by the exams. In Phase VI, the students were graded according to their hard working at the end of the internship program. Additionally, the common complaint of most lecturers of Phase I-V was the decreased number of theoretical hours.

Anatomy elective lectures took part in the elective committees of Phase I and Phase II medical curricula. 
Phase II undergraduate medical students prefer clinical anatomy elective lectures and they tried to make contribution to these lectures. Problem solving about the clinical condition is the part of these lectures which they really were interested. Interestingly, many undergraduate medical students also requested some more problem solving lecture hours related with the other subjects' clinical anatomical conditions.

\section{Discussion}

In order to become a good doctor, finishing a medical school is not enough. A picture of a doctor involves highly educated person who invested a lot in himself and his education. ${ }^{[7]}$ Therefore, there is a great effort for revealing the best medical education methods in all over the world. The university staffs who devote their lives to better medical education discuss new methodologies and try to find the best one for their precious students.

Elective lectures and elective courses are an excellent way to increase students' exposure to special areas which they really are interested. Zapantis et al. ${ }^{[8]}$ designed an elective course in adult acute care medicine using a hybrid delivery system. They concluded that the course increased student exposure to inpatient settings and provided students additional opportunities to communicate effectively, evaluate medical literature and think critically. Marshall and Ashworth ${ }^{[9]}$ developed a women's health course focusing on health promotion, disease prevention and treatment throughout a woman's life span. At the end of the course; excellent student performance in weekly activelearning activities and class participation was observed. However; this did not translate into excellent performance on subsequent formal assessments. Zalihic and Obrdalj ${ }^{[10]}$ organized a minor elective course entitled "communication skills" to medical students and discussed the importance of the subject in doctor-patient therapeutic relationship. Mouradian et al.$^{[1]]}$ developed an oral health elective that targeted first and second year medical students as part of a previously described oral health initiative and oral health curriculum. Evaluations revealed positive shifts in attitudes toward oral health and significant gains in oral health knowledge and self-confidence. At the end of the elective; the medical students rated the course highly and advocated for further integration of oral health into required medical curricula. Eighteen second year medical students participated in the preclerkship HIV elective consisting of lectures, small group sessions, clinical observership, community placements, reading assignments and an HIV counseling and testing workshop. Self-assessment scores of HIV knowledge among the students significantly increased from $78.1 \%$ (prior to elective) to $90.2 \%$ (at the end of the elective).${ }^{[12]}$ Caro-Bruce et al.${ }^{[13]}$ organized a collaborative and multidisciplinary elective course related with the gaps in the areas of abortion and sexual health to a group of first and second year medical students. The elective proved to be a successful collaboration among students, faculty, healthcare providers and resulted in permanent changes in the standard medical school curriculum.

The Bologna Process brought a new approach to medical education. In the study, the effects of Bologna Process to the medical education system of School of Medicine, Hacettepe University was discussed from the point of elective lectures. The outcomes of these data were obtained from the experiences of three academic years. During these three academic years, more than 2500 Phase I - Phase VI medical students' and more than 100 lecturers' opinions and contributions were also discussed. The elective courses must have diversity. Not only the medical elective courses, but also the elective courses of different scientific areas must also be added to medical curriculum. Medical doctors who are highly educated persons must also have a good knowledge about the other scientific areas which they are really interested in. The diversity of the medical and non-medical elective lectures is very important from that point of view.

The number of students who are attending to an elective course is very important. The aim of the elective must be well known and the organization must be perfect prior to lecture or course. In the cases of extreme number of students and low number of electives, it is better to diminish the number of electives which will be taken by the students. This will decrease the number of students per elective lecture and will help to the goals of the course. Additionally, the remaining lecture hours from these electives can be added to the basic medical curriculum. This solution will make the lecturers who are against Bologna Process to feel better. In medical schools with extreme number of students; giving a support to basic medical curriculum will develop the quality of medical education.

Another important point about the electives is their contribution to the grading system. It can be organized freely by each medical school and must always include a less contribution than the basic medical lectures.

The anatomy elective courses seemed very popular among undergraduate medical students. The students require more and more clinical anatomy from the lecturers. However, the adequate number of students for each clinical anatomy elective course must be considered by the lecturers. Additionally, it is ideal to add role modelling to the contents of the courses. Bologna Process and new electives bring a new approach to anatomy and make it very popular among the undergraduate medical students. 


\section{Conclusion}

Medical curriculum investigates new methodologies and new approaches in order to graduate perfect medical doctors. One can never describe the best method in medical education. The number of undergraduate medical students is also a very important factor in medical education and depending upon to it; the medical faculties can choose the best method for their education system. In conclusion, hardworking and excited lecturers combined with ideal number of students can perform the best medical education with any of the methodologies.

Evaluating the Bologna Process and elective courses from the point of anatomy; various elective clinical anatomy courses are essential for drawing the attention. However, the adequate number of students for each clinical anatomy elective course must be considered by the lecturers. Bologna Process and new electives bring a new approach to anatomy and make it very popular among the undergraduate medical students.

\section{References}

1. The European higher education area. The Bologna Declaration of 19 June 1999. Joint declaration of the European ministers of education (Bologna). [Internet]. [cited 2017 Oct 23]. Available from: [http://www. bologna-bergen2005.no/Docs/00-Main_doc/990719bologna_ declaration.pdf ]

2. Christensen L. The Bologna Process and medical education. Med Teach 2004;26:625-9.

3. Cumming A. The Bologna process, medical education and integrated learning. Med Teach 2010;32:316-8.
4. Hensen P. The "Bologna Process" in European higher education: impact of bachelor's and master's degrees on German medical education. Teach Learn Med 2010;22:142-7.

5. Masic I. Quality assessment of medical education at Faculty of Medicine of Sarajevo University - comparison of assessment between students in Bologna process and old system of studying. Acta Inform Med 2013;21:76-82.

6. Patrício M, Harden RM. The Bologna Process - a global vision for the future of medical education. Med Teach 2010;32:305-15.

7. Masic I, Begic E. Efficiency of implementation of the Bologna process at Medical Faculty, University of Sarajevo. Mater Sociomed 2015;27:59-63.

8. Zapantis A, Machado C, Nemire R, Leung S. An elective course in adult acute care medicine using a hybrid delivery system. Am J Pharm Educ 2008;72:105.

9. Marshall LL, Ashworth LE. An elective course in women's health. Am J Pharm Educ 2010;74:12.

10. Zalihiç A, Cerni Obrdalj E. "Fundamental communication skills in medical practice" as minor elective subject. Acta Med Acad 2014;43: 87-91.

11. Mouradian WE, Reeves A, Kim S, Lewis C, Keerbs A, Slayton RL, Gupta D, Oskouian R, Schaad D, Kalet T, Marshall SG. A new oral health elective for medical students at the University of Washington. Teach Learn Med 2006;18:336-42.

12. Chew D, Jaworsky D, Thorne J, Ho M, Andany N, Morin C, Hoffman N, Henshaw C, Rourke SB, Fisher M, Rachlis A. Development, implementation, and evaluation of a student-initiated undergraduate medical education elective in HIV care. Med Teach 2012;34:398-403.

13. Caro-Bruce E, Schoenfeld E, Nothnagle M, Taylor J. Addressing gaps in abortion education: a sexual health elective created by medical students. Med Teach 2006;28:244-7.

Correspondence to: Mustafa F. Sargon, MD

Department of Anatomy, Faculty of Medicine,

Hacettepe University, Ankara, Turkey

Phone: +90 5322468778

e-mail: mfsargon@hacettepe.edu.tr

Conflict of interest statement: No conflicts declared.

This is an open access article distributed under the terms of the Creative Commons Attribution-NonCommercial-NoDerivs 3.0 Unported (CC BY-NCND3.0) Licence (http://creativecommons.org/licenses/by-nc-nd/3.0/) which permits unrestricted noncommercial use, distribution, and reproduction in any medium, provided the original work is properly cited. Please cite this article as: Sargon MF. Bologna Process: elective lectures and internships in medical curriculum and the role of anatomy electives. Anatomy 2017;11(3):137-140. 